\title{
O cabra e a questão cultural nas metáforas animais
}

\author{
Cabra (goat) and cultural issues of animal metaphors
}

\section{Fernanda Carneiro Cavalcanti}

Universidade Estadual do Rio de Janeiro - UERJ - Rio de Janeiro - Rio de Janeiro - Brasil

\begin{abstract}
Resumo: A visão de uma mente corpórea a qual se filia a Teoria da Metáfora Conceptual encontra-se, sobretudo, baseada na ideia de uma mente como resultado da interação entre o programa sensório-motor humano e o meio físico e socioculturalmente situado. Contudo, ao pleitear a existência do que chama de paradoxo da metáfora, Gibbs (2008) identifica uma tensão entre os aspectos universais e variacionais das metáforas. Nessa perspectiva, este artigo busca discutir o papel dos conhecimentos e normas culturais na formação das metáforas animais, especialmente na conceptualização de homem em termos de cabra por parte dos membros da comunidade de Fortaleza-Ceará no Nordeste do Brasil. Para tal fim, o artigo encontra-se organizado em quatro seções, afora a introdução. Discute-se, assim, nas três seções que se seguem à introdução: o modelo cultural da Grande Cadeia do Ser e sua relação com as metáforas animais com base em Kövecses (2010) e Lakoff e Turner (1989); a questão da universalidade nas Metáforas Conceptuais a partir de Kövecses (2005, 2009); a variação cultural das metáforas com ênfase na metáfora animal cabra baseado em Kövecses (2009) e Rodriguez (2009). $\mathrm{Na}$ quinta e última seção, são apresentadas as considerações finais nas quais pondera-se sobre a natureza tanto variacional como potencialmente universal da metáfora animal que licencia a expressão linguística cabra. Nessa perspectiva, argumenta-se que tal metáfora tanto mapearia, em nível genérico, os domínios conceptuais ser humano e animal como os domínios homem e cabra motivados por normas e conhecimentos culturais compartilhados entre os membros da cultura cearense.
\end{abstract}

Palavras-chave: Teoria da Metáfora Conceptual. Metáfora Animal. Cabra.

\begin{abstract}
The vision of an embodied mind which joins the Theory of Conceptual Metaphor is, above all, based on the idea of a mind which results from the interaction between the human sensory-motor program and the physical and social-cultural environment. However, claiming the existence of what he calls the paradox of metaphor, Gibbs (2008) identifies a tension between the universal and variational aspects of metaphors. From this perspective, this article discusses the role of knowledge and cultural norms in the constitution of animal metaphors, especially in the conceptualization of man in terms of cabra (goat) by members of the Fortaleza-Ceara community in northeastern Brazil. For this purpose, the article is organized in four sections, apart from an introduction. In three sections, we discuss the cultural model of the Great Chain of Being and its relation to animal metaphors based on Kövecses (2010) and Lakoff and Turner (1989); the issue of universality in Conceptual Metaphors according to Kövecses $(2005 ; 2009)$; cultural variation of metaphors with emphasis on the animal metaphor cabra (goat) based on Kövecses (2009) and Rodriguez (2009). In the fifth and last section final considerations are presented which point to the animal metaphor cabra (goat) of an example of Conceptual Metaphor both potentially universal since it maps in the generic level the conceptual domains human being and animal, as well as variational since the cross domain mappings of man and cabra (goat) are motivated by norms and shared cultural knowledge among the members of the Fortaleza-Ceara community.
\end{abstract}

Keywords: Theory of Conceptual Metaphor. Animal Metaphor. Cabra (goat). 


\section{Introdução}

A visão de uma mente corpórea a qual se filia a Teoria da Metáfora Conceptual, doravante TMC, encontra-se, sobretudo, baseada na ideia de uma mente como resultado da interação entre o programa sensório-motor humano e o meio físico e socioculturalmente situado. Em conformidade com Gibbs (2010), as normas e os conhecimentos culturais desempenhariam papel relevante na constituição dessa mente corpórea, especialmente na constituição de recursos cognitivos como as Metáforas Conceptuais.

Por outro lado, ao pleitear a existência do que chama de paradoxo da metáfora, Gibbs (2008) identifica uma tensão entre os aspectos universais e variacionais das metáforas. Em outras palavras, para Gibbs (2008), de um lado, a metáfora seria sensibilidade culturalmente criativa e nova; e, de outro lado, ela estaria enraizada em padrões de experiências sensório-motoras comuns a todos os povos. Kövecses (2010) pondera, igualmente, a respeito desse paradoxo. Segundo este autor, mesmo que não se possa prevê a partir da aplicação de princípios gerais quais são as Metáforas Conceptuais de uma língua, seria, porém, pouco plausível esperar que as Metáforas Conceptuais das línguas contrariem as experiências corpóreas humanas universais.

Com base na definição de cultura adotada por Kövecses (2005), segundo a qual cultura é o compartilhamento de um conjunto de entendimentos por parte de membros de uma determinada comunidade, discutimos nesse artigo o papel dos conhecimentos e normas culturais na formação dos recursos cognitivos humanos, especialmente das metáforas animais com base na conceptualização de homem em termos de cabra por parte de membros da comunidade de Fortaleza no Nordeste do Brasil.

Para tal fim, organizamos este artigo em quatro seções, afora esta introdução. Dessa forma, na segunda seção, discutimos o modelo cultural da Grande Cadeia do Ser e sua relação com as metáforas animais com base em Kövecses (2010) e Lakoff e Turner (1989). Na terceira seção, tratamos da questão da universalidade nas Metáforas Conceptuais a partir de Kövecses $(2005,2009)$. Na quarta seção, abordamos a variação cultural das metáforas com ênfase na metáfora animal cabra baseado em Kövecses (2009) e Rodriguez (2009). Na quinta e última seção, apresentamos nossas considerações finais.

\section{Modelo Cultural A Grande Cadeia do Ser}

Segundo Lakoff e Turner (1989), os Modelos Cognitivos Idealizados, doravante MCls, seriam recursos cognitivos responsáveis pela organização dos conhecimentos humanos que, por sua vez, se constituiriam ao menos de duas maneiras diferentes: via nossas experiências diretas, isto é, por meio das estruturas pré-conceptuais (esquemas imagéticos e conceito de nível básico); e/ou via cultura. Ainda para tais autores, além de apresentarem conhecimento de caráter ordinário e não especializado de membros das sociedades humanas, os modelos culturais podem ser tratados na condição de MCls, sobretudo quando se quer destacar sua natureza mental e sua diferença em relação a alguma representação científica pleiteada. Os autores ressaltam ainda que a natureza idealizada dos $\mathrm{MCl}$ deve-se ao fato de que tais modelos não necessariamente se adéquam à realidade.

Em assim sendo, Lakoff e Turner (1989) ponderam que alguns MCls são demasiado abstratos. Ou seja, para tais autores, se compreendemos pessoas, animais e objetos no mundo como tendo atributos, sendo alguns desses atributos considerados essenciais, é porque possuímos um $\mathrm{MCl}$ de caráter muito geral a respeito da natureza das coisas e de seu comportamento. O Modelo Cultural A Grande Cadeia do Ser seria um desses modelos, isto é, um modelo de larga escala, adquirido culturalmente. Com base em tal modelo, atribuiríamos sentido e imporíamos ordem ao universo e aos seres que nos circundam.

Ainda de acordo com os autores em questão, a versão básica desse modelo seria organizada a partir de quatro níveis hierárquicos nos quais o ser humano 
se encontraria no topo seguido dos animais, plantas e objetos. Dessa forma, nós nos pensaríamos como seres superiores aos animais; os animais como seres superiores às plantas; e, as plantas como seres superiores aos objetos. Por outro lado, esses quatro níveis seriam organizados em subníveis compreendidos, por sua vez, como superiores e inferiores de tal forma que estimaríamos, no nível do animal, os cachorros como superiores aos insetos, por exemplo.

Nessa perspectiva, o cachorro seria por nós compreendido com base nas propriedades atribuídas ao inseto, além das propriedades essenciais como vida interior (i.e. desejos, emoções e habilidades cognitivas restritas). No caso dos seres humanos, nós nos compreenderíamos como seres dotados das propriedades dos seres que se encontram nos três níveis abaixo, além das propriedades essenciais como capacidade estética, moral, racional, comunicacional, e de alto nível de consciência.

Lakoff e Turner (1989) avaliam ainda que, na condição de um modelo de caráter esquemático, usado de forma inconsciente por membros de boa parte das culturas humanas, o modelo básico da Grande Cadeia do Ser teria provocado junto às sociedades humanas, profundas consequências sociais e políticas. Isso porque sua organização não estaria apenas pautada em função dos atributos e comportamentos dos seres no mundo. Mas, sobretudo, em função do caráter de superioridade atribuído a determinados seres em relação a outros e, consequentemente, em função da ideia de dominação de determinados seres sobre os demais.

Seria, portanto, por essa razão que acreditaríamos que, no mundo animal, leões, ursos e aves de rapina seriam seres que apresentariam atributos e comportamento superiores aos demais animais. Seria por igual razão que acreditaríamos que nas sociedades humanas: os nobres apresentariam atributos e comportamentos superiores aos camponeses; os homens apresentariam atributos e comportamentos superiores às mulheres; os adultos a crianças; e os mestres aos escravos. Em suma, tal modelo não indicaria apenas como o mundo é, mas, sobretudo como o mundo deve ser.

Lakoff e Turner (1989) abordam, igualmente, o caráter metafórico do modelo em questão. Grosso modo, os autores defendem que o modelo básico da Grande Cadeia do Ser estruturaria Metáforas Conceptuais por meio das quais pessoas seriam compreendidas em termos não humanos e viceversa. Ou seja, como tal modelo estabeleceria domínios de conhecimentos relativos à organização dos seres no mundo, procedimentos metafóricos mapeariam os domínios humanos em termos dos domínios não humanos e vice-versa. Nesse sentido, os autores apontam para o que consideram um dos mais elaborados domínios: o domínio da vida animal, a partir do qual nós compreenderíamos o não humano em termos do humano.

Assim, nós teríamos esquemas bem elaborados nos quais os animais se encontrariam caracterizados em termos de atributos humanos, a exemplo das seguintes caracterizações: porcos são sujos; leões são corajosos; raposas são espertas; cachorros são leais e dependentes; gatos são inconstantes e independentes; lobos são cruéis e assassinos; e gorilas são agressivos e violentos.

Por outro lado, os autores ponderam que os animais agem de forma instintiva e que a visão de esperteza, coragem, inconstância, lealdade, etc. seria, antes de tudo, humana. Assim, quando atribuímos tais características aos animais, nós os estaríamos compreendendo em termos de comportamento humano. Em suma, os autores ressaltam que é tão natural compreendermos atributos não humanos em termos de atributos humanos que temos dificuldade de perceber que tais caracterizações sejam de caráter metafórico.

Em conformidade com esses autores, Kövecses (2010) pondera que os seres humanos caracterizariam metaforicamente os animais em termos de atributos humanos para, em seguida, se compreenderem em termos de animal. Diante de tal fato, Kövecses (2010) afirma que boa parte do comportamento humano parece ser compreendida em termos de comportamento animal a partir da 
Metáfora Conceptual COMPORTAMENTO HUMANO É COMPORTAMENTO ANIMAL. Acrescenta ainda que não apenas o comportamento humano é compreendido em termos de comportamento animal como as pessoas são compreendidas em termos de animais.

Nesse sentido, o referido autor estima que o significado licenciado pelas metáforas COMPORTAMENTO HUMANO É COMPORTAMENTO ANIMAL E PESSOAS SÃO ANIMAIS parece ser primordialmente ofensivo. Contudo, assinala que, apesar de grande parte das metáforas animais mapearem características negativas dos seres humanos, algumas dentre elas não o fariam, a exemplo de MULHER SEXY É GATINHA.

Diante de tal constatação, Kövecses (2010) pleiteia a existência, em nosso sistema conceptual, de metáforas animais de nível genérico, isto é, SER HUMANO É ANIMAL e, de metáforas de nível específico, isto é, PESSOAS ABJETAS SÃO ANIMAIS E PESSOAS SÃO ANIMAIS. Ou seja, as metáforas animais, segundo o autor em questão, seriam metáforas congruentes ou ainda um complexo de metáforas, dentre as quais, uma seria de nível genérico e as demais seriam de nível específico. Observa ainda que seria no âmbito das metáforas de nível específico que ocorreria variação de ordem cultural, já que a metáfora de nível genérico teria caráter primordialmente universal.

Interessante ressaltar a respeito do mapeamento de caráter negativo de ser humano em termos de animal que dados por nós coletados com base em aplicação de cinco questionários junto a 153 residentes em Fortaleza, por ocasião de nossa pesquisa de doutorado, revelam que: $60,0 \%$ dentre 30 sujeitos que responderam a perguntas do questionário 4 concordam com a representação do ser humano em termos de animal contra $30,0 \%$ que não concordam com tal representação; 6,7\% disseram não saber; e 3,3\% não responderam.

Além disso, $43,3 \%$ dentre os mesmos 30 sujeitos que responderam ao questionário 4 não concordaram com 0 fato de ele mesmo ser representado por algum animal contra $43,3 \%$ que concordaram com tal representação.10\% não responderam e 3,3\% disseram não saber. Percebemos, assim, que de acordo com os residentes em Fortaleza, as metáforas animais podem ou não ser avaliadas negativamente.

Nessa perspectiva, a discrepância nas respostas acima analisadas nos leva a inferir que tal tensão se baseia nas metáforas animais SER HUMANO É ANIMAL OU PESSOAS ABJETAS SÃO ANIMAIS, ou ainda PESSOAS SÃO ANIMAIS. Ao que parece, o resultado obtido com a primeira indagação nos induz à hipótese de que os participantes pensaram em ser humano em termos de animal de modo genérico, com base, assim, na metáfora de nível geral SER HUMANO É ANIMAL. Por outro lado, o resultado da segunda indagação nos induz à hipótese de que os participantes pensaram em ser humano em termos de um dado animal, bem avaliado ou não, ou ainda com base nas Metáforas Conceptuais PESSOAS ABJETAS SÃO ANIMAIS e/ou PESSSOAS SÃO ANIMAIS.

Observamos ainda que os animais bem avaliados por tais sujeitos e, por isso, escolhidos majoritariamente para sua representação pessoal seriam borboletas, pássaros e felinos de grande porte. Ou seja, tais sujeitos destacaram, de modo geral, características positivas em relação à borboleta, pelo seu poder de transformação de lavra em um belo inseto. Em relação a pássaros, destacaram o suposto caráter de liberdade associado à capacidade de voar. Em relação a felinos de grande porte, destacaram seu suposto caráter de potência associado à capacidade tanto em defender e proteger seus entes queridos como o de lutar ferozmente pelo que quer.

Com base nos mesmos dados, podemos ainda ponderar que o animal mapeado nas Metáforas Conceptuais pode desempenhar vários papéis em uma dada comunidade. Dessa forma, uma dada metáfora animal poderia mapear características distintas nos domínios conceptuais ser humano e animal. É o caso, por exemplo, do mapeamento 
homem em termos de cabra que ora mapeia homem perseverante e valoroso, ora mapeia homem rude.

Por fim, ainda consoante Kövecses (2010), o domínio fonte animal é um dos domínios extremamente produtivos. Isso porque os seres humanos são frequentemente compreendidos em termos de propriedades atribuídas aos animais, segundo dados coletados pelo autor em questão em dicionários e pesquisas realizadas por estudiosos da metáfora. Ademais, o autor chama atenção para o fato de que não apenas entendemos ser humano em termos de animal como também situações ou coisas. Nesse sentido, podemos pensar nas seguintes expressões em português do Brasil: uma festa animal; um carro animal, a vida voa, o tempo voa. 0 autor também ressalta a compreensão de domínios abstratos em termos de partes dos corpos de animal a exemplo das seguintes expressões em português do Brasil: tire as patas de cima de mim; um é o focinho do outro; ou ela tem memória de elefante.

\section{A Universalidade nas Metáforas Conceptuais}

De acordo com Kövecses (2005), a TMC é abordada tanto por Lakoff e Johnson ([1980] 2002) como por Grady (1997) com base, sobretudo nas experiências corpóreas humanas mais básicas, a exemplo da metáfora primária: AFEIÇÃO É CALOR, que licenciaria, por exemplo, expressões linguísticas em português do Brasil como nós temos uma relação calorosa. Isso porque, segundo Kövecses (2005), não seria surpresa para ninguém que afeição seja associada a calor e não a frio, considerando que tal correlação entre as experiências de afeição e de calor se teria dado de forma inconsciente, remontando à nossa mais tenra idade quando éramos acolhidos junto ao corpo de alguém com a função de mãe. Em outras palavras, a TMC, ao contemplar a conceptualização de experiências humanas mais básicas, enfatiza, sobretudo, o caráter potencialmente universal das Metáforas Conceptuais.

Contudo, Kövecses (2005) pondera que se observarmos a relação entre metáforas e as línguas humanas, temos a nítida impressão de que há tão grande número de Metáforas Conceptuais de caráter não universal quanto de Metáforas Conceptuais com caráter potencialmente universal. Considera, dessa forma, que as Metáforas Conceptuais, na condição de recurso cognitivo sistemático responsável pela conceptualização humana de grande parte dos conceitos mais abstratos, variam igualmente de cultura para cultura, a exemplo da conceptualização de amor em termos de jornada, de unidade e de caça em culturas como a americana, húngara e chinesa, respectivamente.

Por essa razão, Kövecses (2005) estima que as Metáforas Conceptuais teriam de ser compreendida a partir da interconexão entre os níveis linguístico, conceptual, sociocultural, neural e corpóreo. Por outro lado, a ideia central defendida por teóricos da TMC é de que pelo fato de os seres humanos apresentarem programa sensório-motor similar e o meio físico não diferir tanto de cultura para cultura, a maior parte das Metáforas Conceptuais existentes no sistema conceptual humano seriam igualmente similares, portanto, universais. Apesar de questionar essa visão com base em evidências relevantes de variação metafórica em estudos e pesquisas empreendidas, Kövecses (2005) menciona trabalhos nos quais o caráter universal da Metáfora Conceptual fora evidenciado.

Em sua obra Metaphor in Culture, o autor discute resultados de duas pesquisas que foram realizados no domínio das emoções, particularmente de felicidade e de raiva. $\mathrm{O}$ conceito de felicidade foi examinado nas línguas chinesa, húngara e inglesa. $O$ conceito de raiva nas línguas chinesa, húngara, inglesa, japonesa, polonesa, wolof e zulu. $\mathrm{Na}$ pesquisa realizada em língua inglesa, fora encontrado um grande número de Metáforas Conceptuais mapeando o conceito de felicidade, dentre as quais FELICIDADE É PARA CIMA (I'mfelling up [Estou me sentindo para cima]). A mesma Metáfora Conceptual fora encontrada em língua chinesa (Tahen Gao-xing/ $\mathrm{He}$ is very high-spirited/happy [Ele é alto astral/feliz] e húngara (Ez a filmfeldobott./Thisfilmup-threw-me [ Este filme me jogou para cima].(Cf.KÖVECSES, 2005, p. 39). Quanto ao conceito raiva, os estudos 
realizados em língua inglesa, chinesa, japonesa, húngara, wolof e zulu encontraram a Metáfora Conceptual UMA PESSOA COM RAIVA É UM RECIPIENTE PRESSURIZADO. Kövecses sumariza tais achados da seguinte forma:

Em todas essas línguas, a metáfora do RECIPIENTE foi identificada. Nela, o RECEPIENTE se encontra mapeado em termos de pressão devido à ação de calor ou de outros fatores. Tal metáfora apresenta as seguintes correspondências ou mapeamentos em termos de 'raiva':

O recipiente com algum tipo de substância ou objeto $=$ a pessoa que está raivosa.

A substância ou objetos do recipiente $=a$ raiva.

A pressão da substância ou objetos no recipiente $=\mathrm{a}$ força da pessoa raivosa .

A causa da pressão $=$ a causa da força da raiva mantendo a substância ou objetos no recipiente $=$ controle da raiva .

A substância ou objetos saindo do recipiente $=$ a expressão de raiva.

Dessa forma, argumento que esse mapeamento produz uma cena ou situação para 'raiva' na qual há uma força dentro das pessoas de sorte que tal força faz as pessoas agirem de maneira a se despressurizarem. A causa, a força e a estrutura da expressão forçado continua a ser um mistério e um acontecimento completamente aleatório na evocação da metáfora do RECIPIENTE PRESSURIZADO. Por outro lado, por meio de seu mapeamento detalhado, tal metáfora fornece uma estrutura coerente para os vários conceitos de 'raiva' em diferentes línguas. (2005, p. 39-40). (Tradução Nossa).

Kövecses (2005) assinala ainda que os estudos acima mencionados revelaram evidências de que certas Metáforas Conceptuais, particularmente no âmbito das Metáforas Conceptuais de nível genérico, apresentam caráter potencialmente universal. Acrescenta, no entanto, a título de conclusão, que as Metáforas Conceptuais que foram particularmente estudadas estão baseadas em experiências humanas universais, a exemplo das emoções de raiva e felicidade.

\section{As Metáforas e a Variação Cultural}

Kövecses (2009) avalia que enquanto os linguistas cognitivos tendem a se perguntar o que é metáfora e como ela funciona na mente, antropólogos, interessados em estudar as Metáforas Conceptuais, tendem a focar-se na questão acerca do papel da metáfora nos diferentes contextos socioculturais. Nesse sentido, considera desafio tanto para os cientistas cognitivos como, mais especificamente, para os linguistas, o desenvolvimento de uma visão que compreenda a universalidade e a diversidade do pensamento metafórico. Ou seja, de acordo com a visão preconizada por Kövecses, tais especialistas devem debruçar-se no fenômeno assinalado por Gibbs (2008) como paradoxo da metáfora. Para tanto, sugere a necessidade de que se formule uma teoria cognitivo-cultural que contemple as variações metafóricas e suas causas.

Com esse intuito, Kövecses (2009) advoga a favor da ideia de que as Metáforas Conceptuais variariam ora no âmbito de duas ou mais culturas, ora no âmbito de uma mesma cultura. No âmbito de duas ou mais culturas, haveria, dentre outras, variação no âmbito das metáforas de nível específico em função de aspectos socioculturalmente situados, a exemplo da variação da Metáfora Conceptual UMA PESSOA COM RAIVA É UM RECIPIENTE PRESSURIZADO nas culturas supracitadas.

Dessa forma, no nível genérico, tal metáfora, conforme assinalado na seção anterior, apresentaria caráter potencialmente universal. No entanto, em nível específico, tal metáfora variaria em função dos diferentes preenchimentos culturais, a exemplo da variação em termos de tipo de recipiente pressurizado na língua japonesa e na língua zulu. $\mathrm{Na}$ língua japonesa, o recipiente pressurizado seria barriga ao passo que na língua zulu, trata-se do coração.

Quanto à variação das Metáforas Conceptuais no âmbito de uma mesma cultura, em consonância com os postulados da Sociolinguística, da Sociologia e da Antropologia, segundo os quais as línguas não são monolíticas, Kövecses (2009) postula, 
igualmente, que as Metáforas Conceptuais variam, em uma dada comunidade em termos sociais regionais, étnicos, históricos e individuais. Apesar de destacar que não há ainda estudos sistemáticos a respeito dessa perspectiva, o autor menciona que haveria evidência de variação de Metáforas Conceptuais licenciando diferentes expressões linguísticas em inglês usadas por homens quando se dirigirem às mulheres e vice-versa. Seriam expressões licenciadas por metáforas animais usadas tanto por homens ao tratarem as mulheres, por exemplo, de coelhinha [bunny]; gatinha [kitten]; passarinho [bird]; franguinha [chic] como por mulheres ao tratarem os homens, por exemplo, de urso [bear] e tigre [tiger].

Nesse sentido, consideramos a metáfora animal que licencia a expressão linguística cabra como exemplo de variação metafórica no âmbito de uma mesma cultura. Isso porque a conceptualização homem em termos de cabra é particularmente encontrada no Nordeste do Brasil. Se de início tal conceptualização era associada aos membros da zona rural da região em questão, atualmente, ela se encontra presente na zona urbana, já que, de acordo com o resultado de nossa pesquisa de doutorado, os estudantes da Universidade Federal do Ceará (UFC) ou Universidade de Fortaleza (UNIFOR) da cidade de Fortaleza aceitam que um homem seja compreendido em termos de cabra.

Segundo ainda os resultados dessa pesquisa, a metáfora animal que licencia a expressão linguística cabra mapearia os domínios conceptuais animal e ser humano em nível genérico, isto é, SER HUMANO É ANIMAL, e em nível específico, isto é, PESSOAS ABJETAS SÃO ANIMAIS e PESSOAS SÃO ANIMAIS ou ainda HOMEM MESTIÇO SERTANEJO É CABRA e HOMEM VIRIL VALENTE TRABALHADOR É CABRA, respectivamente. Essas metáforas específicas estariam sendo motivadas por determinados conhecimentos e normas culturais compartilhados entre os membros da cultura nordestina, tal qual nos informa Cascudo ao afirmar que:
Chamamos cabra ao filho do mulato com a negra e não é simpático ao folclore sertanejo. Não há doce ruim nem cabra bom. O tratamento de 'cabra' é insultoso. Ninguém gosta de ouvir o nome. [...]. Todas as estórias referentes aos 'cabras' são pejorativas e são eles entes malfejos, ingratos, traiçoeiros. (2009, p. 60)

Com base nessa afirmação, pleiteamos que a metáfora específica PESSOAS ABJETAS SÃO ANIMAIS estaria mapeando características negativas dos domínios conceptuais homem e cabra motivada por crença de que a mestiçagem é algo negativo. Observamos, particularmente, que o atributo mestiço é mapeado em termos de traição e de má índole. Há que se observar ainda que as etnias que dão origem ao cabra elencadas por Cascudo (2009) são etnias socialmente desprestigiadas na cultura brasileira. Ademais, tal homem mestiço seria residente de uma das regiões mais pobres e desassistidas do Brasil: $O$ Sertão Nordestino.

A visão acerca do caráter cultural e não apenas cognitivo das metáforas, sobretudo, das metáforas animais é igualmente advogada por Rodriguez (2009). Tal autora realizou estudo no qual analisou 0 papel de metáforas animais no licenciamento de expressões linguísticas referentes à condição feminina nas línguas espanhola e inglesa. Sua tese é a de que as metáforas animais se constituem em recursos cognitivos que projetam experiências relativas à construção de identidades sociais e de gêneros. Ou ainda, mais particularmente, de que as metáforas animais motivam e formulam conceitos negativos a respeito da condição feminina.

Dessa forma, Rodriguez (2009) conclui que tais metáforas seriam motivadas por crenças e valores de determinado grupo de indivíduos representado pelo macho branco e heterossexual. Tal grupo, na condição de Self, se constituiria como cânone social em detrimento de determinados grupos de indivíduos, a exemplo das mulheres, que, na condição do Outro, contrariaria essa ordem canônica, passando a ser avaliados como inferiores ou marginais. Rodriguez (2009) afirma ainda que metáforas animais, ao apresentarem caráter sociocultural, projetam atitudes e crenças de 
determinadas comunidades em relação não apenas a determinados animais, mas em relação a determinados animais em termos de determinados grupos sociais.

Nesse sentido, a autora estima que a dimensão cultural das metáforas animais as torna importantes veículos para transmissão e perpetuação de crenças sociais a partir de determinadas práticas discursivas, a exemplo da transmissão e perpetuação da condição feminina em termos de objeto dos desejos sexuais do macho branco heterossexual nas comunidades de falantes de língua espanhola e inglesa. Em outras palavras, os usuários das línguas em questão transmitiriam e perpetuariam crenças sociais em relação aos grupos considerados marginais ou inferiores, no caso, as mulheres com base na conceptualização PESSOAS SÃO ANIMAIS e PESSOAS ABJETAS SÃO ANIMAIS.

Nessa perspectiva, consideramos que a metáfora animal cabra, particularmente a metáfora específica PESSOAS ABJETAS SÃO ANIMAIS, isto é, HOMEM MESTIÇO SERTANEJO É CABRA, seria motivada por atitudes e crenças da sociedade brasileira, principalmente, da sociedade nordestina, em relação ao grupo social homem mestiço sertanejo. Embora seja plausível afirmar que homem mestiço e sertanejo, na condição de grupo marginal e inferior, esteja sendo mapeado negativamente pela metáfora animal em questão, restaria a pergunta: Por que homem mestiço sertanejo está sendo mapeado em termos particularmente do animal cabra? Ou ainda, que tipo de norma cultural motivaria a metáfora conceptual de nível específico HOMEM MESTIÇO SERTANEJO É CABRA?

É interessante ressaltar a esse respeito que ao fazer referência à figura masculina como cabra, Cascudo (2009) também se reporta ao animal. Ao discorrer sobre a história desse animal, Cascudo (2009) nos informa que do convívio com tal animal teriam surgido histórias segundo as quais tanto o bode quanto a cabra desapareciam por uma hora durante o dia para ir ter com o coisa ruim. Tal autor avalia que:
Desta participação religiosa a cabra nunca se libertou. Não se aproximou de santo algum e não há lenda ou história em que figure como elemento favorável. Familiar, doméstica, da intimidade sertaneja, não inspira confiança integral ao povo. Em lenda alguma da literatura oral cristã comparece com a cabra num plano de boa educação ou afeto. $\mathrm{Na}$ etiologia de sua voz, há uma condenação popular que tivemos de Portugal: 'Cristo nasceu!' - cantou o galo. 'Onde' - muge o boi. 'Em Belém!', baliu a ovelha. 'Mentes, mentes' - resmungou a cabra, guardando até hoje a negativa gaguejada e pagã. (2009, p. 61)

Outro aspecto interessante diz respeito à crença a respeito dos perigos do leite de cabra. Segundo Cascudo (2009, p. 62), acreditava-se, sobretudo no Sertão do Nordeste, que o leite da cabra poderia transmitir "o caráter inquieto, buliçoso, arrebatado, da amamentadora. [Ou ainda de que] o menino, demasiado vivo, arteiro, endiabrado, tem a justificativa no leite da cabra". Dessa forma, consideramos que há uma correlação de base cultural entre os domínios conceptuais homem e cabra, mais especificamente entre os atributos mestiço sertanejo malfejo, ingrato e traiçoeiro de homem e o atributo endiabrado da cabra.

Por outro lado, embora Cascudo (2009) não aponte para nenhum tipo de aspecto positivo na compreensão do que seja um cabra, há evidências de que o conceito CABRA seria, igualmente, motivado por tais aspectos. Ou seja, o fato de a expressão linguística cabra também se referir a homem viril, valente, trabalhador até mesmo heroico se constitui em evidências de que tal expressão é também motivada por metáforas específicas que mapeiam características positivas da relação homem mestiço em termos de cabra.

Nesse sentido, Freyre (2004), ao citar folclorista Rodrigues de Carvalho, discorda deste folclorista por não aceitar que o caráter mestiço do cabra o faça 'irrequieto, inconstante e nem sempre leal'. Por outro lado, Freyre (2004) não contesta a afirmação do folclorista em questão quando este declara que o cabra estar associado a grande número de história no qual é tratado na condição de herói e é reconhecido por sua coragem, seu poder de sedução, seu vigor sexual e suas vantagens físicas. Seria de 
acordo com essa visão, ainda segundo Freyre (2004), que se cunharam expressões como: 'cabra danado', 'cabra escovado', 'cabra bom' e 'cabra de confiança'. Além disso, para Freyre:

A história social do Nordeste da Cana-deAçúcar está ligada, como talvez a de nenhuma outra região de Brasil, ao esforço do mestiço, ou antes, do cabra. Um esforço que se tem exercido debaixo de condições duramente desfavoráveis. Mas, mesmo assim, notável pelo que tem construído e realizado. (2004, p. 171).

Considerando que a história social do Nordeste da Cana-de-Açúcar remonta às origens da história do Brasil, já que o plantio da cana-de-açúcar no Nordeste data de meados do século XVI, seria plausível afirmar que o cabra teria sido um dos primeiros tipos originalmente brasileiros. Não é por acaso que Freyre (2004, p. 50) declara que "primeiro se fixaram e tomaram fisionomia brasileira os traços, os valores, as tradições portuguesas que, junto com as africanas e as indígenas, constituiriam aquele Brasil profundo, que hoje se sente ser os mais brasileiros". Tais fatos nos faz inferir que, para Freyre (2004), o lugar e o papel do cabra na história do Brasil deve ser considerado de forma valorosa.

Em suma, seria plausível considerar o fato de que a expressão linguística cabra é licenciada por metáfora de nível genérico SER HUMANO É ANIMAL e por metáforas de nível específico PESSOAS ABJETAS SÃO ANIMAIS e PESSOAS SÃO ANIMAIS. As metáforas especificas se encontrariam motivadas ora por crenças segundo as quais a cabra seria um animal que teria parte com o diabo e seu leite poderia transmitir características diabólicas aos garotos que se alimentam dele, ora por crenças segundo as quais o cabra é genuinamente brasileiro/nordestino, teimoso, persistente e resistente assim como a cabra que resiste às precárias condições de vida no Sertão nordestino.

\section{Considerações finais}

Kövecses (2009) pondera que muitos processos cognitivos operam na conceptualização metafórica de forma que não seria razoável tratar apenas da identificação da relação entre dois domínios conceptuais no mapeamento metafórico. Dessa forma, sugere que sejam investigados os diversos aspectos de variação metafórica para que se possa propor uma visão cognitivo-cultural da Metáfora Conceptual. Acrescenta ainda que tal visão se constituiria em uma complementação à visão experiencial postulada, de maneira majoritária, pelos estudiosos da Metáfora Conceptual.

Nesse sentido, estimamos que a discussão acerca da conceptualização de homem em termos de cabra por membros da comunidade de FortalezaCeará poderá contribuir ainda que modestamente para que desenvolvamos uma visão cognitivo-cultural. Isso porque defendemos que a metáfora animal que licencia a expressão linguística cabra ora se constitui em exemplo de Metáforas Conceptuais potencialmente universal ao mapear em nível genérico os domínios conceptuais ser humano e animal, ora apresenta caráter variacional ao mapear os domínios homem e cabra motivada por normas e conhecimentos culturais compartilhados entre os membros da cultura cearense, especialmente da comunidade fortalezense. Em outras palavras, estimamos que Metáforas Conceptuais, a exemplo da metáfora animal aqui analisada no âmbito de uma mesma cultura, isto é, da comunidade dos falantes de língua portuguesa do Nordeste do Brasil, além de apresentarem aspectos potencialmente universais, podem variar em função de determinados entendimentos compartilhados por parte de determinados membros de uma comunidade, no caso a cultura nordestina, acerca do papel que um determinado animal, no caso a cabra, exerce em tal comunidade. 


\section{Referências}

CASCUDO, Luís Câmara. Coisas que o povo diz. 2. ed.São Paulo: Globo Editora, 2009. 1. ed., 1968.

CAVALCANTI, Fernanda C. A análise da expressão convencional cabra sob a perspectiva da teoria dos modelos cognitivos idealizados. 2014. 246p. Tese. (Doutorado em Linguística). Programa de Pós-Graduação em Linguística, Universidade Federal do Ceará, Fortaleza, 2014.

FREYRE, Gilberto.Nordeste. 7. ed. São Paulo: Global Editora, 2004. 1. ed, 1937.

GIBBS, Raymond. Metaphor and thought: the state of the art. In: GIBBS, Raymond. (Ed.). The Cambridge handbook of metaphor and thought.NewYork: Cambridge University Press, 2008.p.3-13.

GIBBS, Raymond. The wonderful, chaotic, creative, heroic, challenging world of researching and apply metaphor. In: LOW, Graham et al. (Ed.), Researching and applying metaphor in the real world. Human cognitive processing 26. John Bejamins Publishing Company, 2010. p.1-18.

GIBBS, Raymond. Evaluating conceptual metaphor theory. Discourse Processes, New York: Routlegde. n. 48. p. 529-562, 2011.

GRADY, Joseph.Foundations of meaning: primary metaphors and primary scenes. 1997. PhD Dissertation. Graduate Division, University of California, Berkeley, 1997.

KÖVECSES, Zoltán. Metaphor in culture: universality and variation. Cambridge: Cambridge University Press, 2005.

KÖVECSES, Zoltán. Variation in Metaphor. In: VIEIRA, Josalba; VEREZA, Solange (Org.). Ilha do Desterro. Florianópolis. n. 53. p.13-39, 2007.

KÖVECSES, Zoltán. Universalidade versus nãouniversalidade metafórica. In: SIQUEIRA, Maity (Org.). Cadernos de Tradução. Porto Alegre, n. 25,p.257-277, jul-dez. 2009.

KÖVECSES, Zoltán.Metaphor: a practical introduction.2. ed. Oxford: Oxford University Press, 2010.

LAKOFF, George. Women, fire and dangerous things: what categories reveal about the mind. University of Chicago Press, 1987.

LAKOFF, George; JOHNSON, Mark.Metáforas da vidacotidiana. São Paulo: EDUC e Mercado das Letras, (1980), 2002.
LAKOFF, George; TURNER, Mark.More than cool reason: a field guide to poetic metaphor. Chicago: University of Chicago Press, 1989.

MACEDO, Ana Cristina Pelosi de. Cognição e linguística. In: MACEDO, Ana Cristina Pelosi de; FELTES, Heloísa Pedroso de Moraes; FARIAS, Emília Maria Peixoto (Orgs.). Cognição e linguística: explorando territórios, mapeamentos e percursos. Porto Alegre: Edipucrs, 2008. p. 9-37.

RODRIGUEZ, Irene Lopéz. Women, biches, chickens and vixens: animal metaphors for women in English and Spanish.Revista de EstudiosCulturales de laUniversitatJaume I. v.VII. p. 77-10, 2009.

$\mathrm{ROSCH}$, Eleanor et al. Basic object in natural categories.CognitivePsychology, n.8. p. 382439, 1976.

SILVA, Augusto Soares da. Introdução: linguagem, cultura e cognição, ou a linguística cognitiva. In: SILVA, Augusto Soares da; TORRES, Amadeu; GONÇALVES, Miguel (Org.). Linguagem, cultura e cognição. Coimbra: Livraria Almedina, 2004. v.1. p. 1-18.

WITTGENSTEIN, Ludwig. Tratado lógicofilosófico/Investigações filosóficas. Lisboa. FundaçãoCalousteGulbenkian, 1987.

YU, Ning. Metaphor from body and culture. In: GIBBS, Raymond (Ed.).The Cambridge handbook of metaphor and thought. Cambridge: Cambridge University Press. p.247-261, 2008. 